\title{
Classification Of Solutions Of Second Orderneutraldelay Dynamic Equations On Timescales
}

\author{
P.Rami Reddy ${ }^{1}$, N.Sikender ${ }^{2}$ and M.Venkata Krishna ${ }^{3}$ \\ ${ }^{I}$ (Mathematics Department, Govt. Degree college Khairathabad,Osmania University, Hyderabad, India) \\ 2,3 (Mathematics Department, Osmania University, Hyderabad, Telangana, India)
}

\begin{abstract}
In this paper, the authors classified all solutions of the second order nonlinearneutral delay dynamic equations into four classes and obtained conditions for the existence/non-existence of solutions in these classes. Examples are included to illustrate the validation of the main results.
\end{abstract}

Keywords; second order, neutral dynamic equations, oscillatory solution, weakly oscillatory solution, asymptotic behavior, time scales.

\section{Introduction}

We consider the second order nonlinear neutral delay dynamic equation

$$
\left\{\mathrm{r}(\mathrm{t})[x(\mathrm{t})+\mathrm{p}(\mathrm{t}) \mathrm{x}(\alpha(\mathrm{t}))]^{\Delta}\right\}^{\Delta}+\mathrm{q}(\mathrm{t}) \mathrm{f}(\mathrm{x}(\beta(\mathrm{t})))=0, \quad \mathrm{t} \in\left[\mathrm{t}_{0}, \infty\right)(1.1)
$$

Where $\mathrm{T}$ is a time scale with sup $\mathrm{T}=\infty$ and the time scale interval $\left[\mathrm{t}_{0}, \infty\right)_{T}=\left[\mathrm{t}_{0}, \infty\right) \cap \mathrm{T}$. Subject to the conditions:

$$
\begin{aligned}
& \left(\mathrm{H}_{1}\right) \quad \mathrm{r} \in \mathrm{C}_{\mathrm{rd}}^{1}\left(\left[\mathrm{t}_{0}, \infty\right)_{\mathrm{T}},(0, \infty)\right), \mathrm{p} \in \mathrm{C}_{\mathrm{rd}}^{2}\left(\left[\mathrm{t}_{0}, \infty\right)_{\mathrm{T}}, \mathrm{R}\right) ; \\
& \left(\mathrm{H}_{2}\right) \quad \mathrm{q} \in \mathrm{C}_{\mathrm{rd}}\left(\left[\mathrm{t}_{0}, \infty\right)_{\mathrm{T}}, \mathrm{R}\right) \text { and } \mathrm{q} \text { does not vanish eventually; } \\
& \left(\mathrm{H}_{3}\right) \quad \mathrm{f} \in \mathrm{C}^{1}(\mathrm{R}, \mathrm{R}) \text { such thatf satisfies uf(u)>0 for } u \neq 0, \mathrm{f}^{\prime}(\mathrm{u}) \geq 0 \text { for } \mathrm{u} \in \mathrm{R} ; \\
& \left(\mathrm{H}_{4}\right) \quad \alpha, \beta \in \mathrm{C}_{\mathrm{rd}}\left(\left[\mathrm{t}_{0}, \infty\right)_{\mathrm{T}}, \mathrm{R}\right) \text { are strictly increasing functions such that } \\
& \qquad \alpha(\mathrm{t}) \leq \mathrm{t}, \beta(\mathrm{t}) \leq \mathrm{t} \text { and } \lim _{\mathrm{t} \rightarrow \infty} \alpha(\mathrm{t})=\infty=\lim _{\mathrm{t} \rightarrow \infty} \beta(\mathrm{t}) .
\end{aligned}
$$

Let $\mathrm{t}_{\mathrm{x}} \in\left[\mathrm{t}_{0}, \infty\right)_{\mathrm{T}}$ such that $\alpha(\mathrm{t}) \geq \mathrm{t}_{0}, \beta(\mathrm{t}) \geq \mathrm{t}_{0}$ for allt $\in\left[\mathrm{t}_{\mathrm{x}}, \infty\right)_{\mathrm{T}}$. By a solution of equation (1.1)weshallmeanafunctionx $\in C_{r d}\left(\left[t_{x}, \infty\right)_{T}\right.$, R) whichhasthepropertiesx $(t)+p(t) x(\alpha(t)) \in C_{r d}^{1}\left[t_{x}, \infty\right)_{T}$ $\operatorname{andr}(\mathrm{t})[\mathrm{x}(\mathrm{t})+\mathrm{p}(\mathrm{t}) \mathrm{x}(\alpha(\mathrm{t}))] \in \mathrm{C}_{\mathrm{rd}}^{1}\left[\mathrm{t}_{\mathrm{x}}, \infty\right)_{\mathrm{T}}$ satisfiesequation $(1.1)$ on $\left[\mathrm{t}_{\mathrm{x}}, \infty\right)_{\mathrm{T}}$. As is customary, a solution of equation $(1.1)$ is oscillatory solution (OS) if it is neither eventually positive nor eventually negative, otherwise it is called non-oscillatory. A non-oscillatory solution $\mathrm{x}(\mathrm{t})$ of equation (1.1) is said to be weakly oscillatory solution (WOS) if $x(t)$ is non-oscillatory and $x^{\Delta}(t)$ is oscillatory for large values oft $\in\left[t_{0}, \infty\right)$.

A major task of mathematics today is to harmonize the continuous and the discrete, to include them inone comprehensive mathematics and eliminate obscurity from both.

The theory of time scales, which has recently received a lot of attention was introduced by StefenHilger in his Ph.D thesis in 1988 in order to unify continuous and discrete analysis (see [1]). Since then, there has been extensive improvement in the oscillation theory of dynamic equations has been increasing (see[[2]-[5]]), and the references cited therein. We are interesting in this paper by classifying all solutions of (1.1) into four classes and obtainconditions for existence/nonexistence of solutions in these classes. Our results in this papernot only new for differential and difference equations, but are also new for the generalized difference and q-difference equations and many other dynamic equations on time scales.

Some authors have paid their attention related to the existence/nonexistence of solutions of various equations. For example (see [8]), Cecchi et. al. considered the following differential equations

$$
\begin{gathered}
{\left[p(t) h(x) x^{\prime}(t)\right]^{\prime}+q(t) f(x(g(t)))=0,(1.2)} \\
\text { and } \\
{\left[p(t) h(x) x^{\prime}(t)\right]^{\prime}+q(t) f(x((t)))=0,(1.3)}
\end{gathered}
$$

Agarwal et. al. (see [11]) considered the following difference equation

$$
\Delta\left(\mathrm{p}_{\mathrm{n}} \Delta\left(\mathrm{y}_{\mathrm{n}}+\mathrm{h}_{\mathrm{n}} \mathrm{y}_{\mathrm{n}-\mathrm{k}}\right)\right)+\mathrm{q}_{\mathrm{n}+1} \mathrm{f}\left(\mathrm{y}_{\mathrm{n}+1-\mathrm{k}}\right)=0, \quad \mathrm{n} \in\{0,1.2 \ldots \ldots\}(1.4)
$$

Where $\Delta$ is the forward difference operator, Sabah Hafez Abdallah (see [10]) considered the following differential equation

$$
\left[\mathrm{p}(\mathrm{t})(\mathrm{x}(\mathrm{t})+\mathrm{h}(\mathrm{t}) \mathrm{x}(\mathrm{t}-\tau))^{\prime}\right]^{\prime}+\mathrm{q}(\mathrm{t}) \mathrm{x}^{\alpha}(\mathrm{t}-\sigma)=0,(1.5)
$$

where $\tau$ and $\sigma$ are non-negative real numbers, and many authors (see[11]-[14]) considered various differential/difference equations, but all are studied the above equations by classifying all solutions into four 
classes such asM $\mathrm{M}^{+}, \mathrm{M}^{-}$, OS and WOS and obtained criteria for the existence/non-existence of solutions in these classes.

Motivated and inspired by the papers mentioned above, in this paper we consider the equation (1.1), and deals the cases when $\mathrm{q} \geq 0$ and $\mathrm{q}$ changes the sign for all large $\mathrm{t} \in\left[\mathrm{t}_{0}, \infty\right)_{T}$, to give sufficient conditions in order that every solution of equation (1.1) is either oscillatory or weakly oscillatory and to study the asymptotic nature of non-oscillatory solutions of equation (1.1). With respect to their asymptotic behavior all the solutions of equation (1.1) may be priori divided in to the following classes:

$$
\begin{aligned}
& M^{+}=\left\{x \in S: \exists t_{x} \in\left[t_{0}, \infty\right)_{T} \text { such that } x(t) x^{\Delta}(t) \geq 0 \text { for } t \in\left[t_{x}, \infty\right)_{T}\right\} ; \\
& M^{-}=\left\{x \in S: \exists t_{x} \in\left[t_{0}, \infty\right)_{T} \text { such that } x(t) x^{\Delta}(t) \leq 0 \text { for } t \in\left[t_{x}, \infty\right)_{T}\right\} ; \\
& \text { OS }=\left\{x \in S: \exists \text { a sequence } t_{n} \in\left[t_{0}, \infty\right)_{T}, t_{n} \rightarrow \infty \text { such that } x\left(t_{n}\right) x\left(t_{n+1}\right) \leq 0\right\} \\
& \text { WOS }=\left\{x \in S: x(t) \text { is non oscillatory for large } t \in\left[t_{0}, \infty\right)_{T}, \text { but } x^{\Delta}(t) \text { oscillates }\right\} .
\end{aligned}
$$

With a very simple argument we can prove that $\mathrm{M}^{+}, \mathrm{M}^{-}$, OS, WOS are mutually disjoint. By the above definitions, it turns out that solutions in the class $\mathrm{M}^{+}$are eventually either positive non-decreasing or negative non-increasing, solutions in the class $\mathrm{M}^{-}$are eventually either positive non-increasing or negative nondecreasing, solutions in the class OS are oscillatory, and finally solutions in the class WOS are weakly oscillatory.

In Section 2, we discuss definitions and preliminaries of time scale calculus. In Section 3, we obtain sufficient conditions for the existence/non-existence in the above said classes. In Section 4, we discuss the asymptotic behavior of solutions in the class of $\mathrm{M}^{+}$andM- $\mathrm{M}^{-}$.Finally section 5 , follows conclusion.

\section{Definitions and Preliminaries}

For completeness in the paper, we find it useful to recall the following notions about time scale theory. A time scale is a nonempty closed subset of real numbers. On a time scale [ denoted by T], the forward jump operator, the backward jump operator, and the graininess function are defined as follows respectively

$$
\sigma(\mathrm{t})=\inf \{\mathrm{s} \in \mathrm{T}: \mathrm{s}>t\}, \quad \rho(\mathrm{t})=\sup \{\mathrm{s} \in \mathrm{T}: \mathrm{s}<t\}, \quad \mu(\mathrm{t})=\sigma(\mathrm{t})-\mathrm{t}, \quad \mathrm{t} \in \mathrm{T}
$$

where inf $\emptyset=\operatorname{supT}$ (i.e., $\sigma(\mathrm{t})=\mathrm{t}$ if $\mathrm{T}$ has a maximum $\mathrm{t}$ )

$\sup \emptyset=\inf \mathrm{T}$ (i.e., $\rho(\mathrm{t})=\mathrm{t}$ if $\mathrm{T}$ has a minimum $\mathrm{t}$ ), here $\emptyset$ denotes the empty set.

A point $t \in T$ is said to be left-dense if $t>\inf T$ and $\rho(t)=t$, right-dense if $t<\operatorname{supT}$ and $\sigma(t)=t$, leftscattered if $\rho(t)<t$, right-scattered if $\sigma(t)>t$, and isolated if $\rho(t)<t<\sigma(t)$.

A function $\mathrm{f}: \mathrm{T} \rightarrow \mathrm{R}$ is said to be right-dense continuous (rd-continuous) provided it is continuous at each right-dense points in $\mathrm{T}$ and its left-sided limit exists (finite) at left-dense points in $\mathrm{T}$. The set of all such rdcontinuous functions is denoted by $\mathrm{C}_{\mathrm{rd}}(\mathrm{T}, \mathrm{R})$.

We also need the set $T^{k}$ : If $T$ has a left-scattered maximum $m$, then $T^{k}=T-\{m\}$ Otherwise, $T^{k}=T$.

Let $\mathrm{f}: \mathrm{T} \rightarrow \mathrm{R}$, then we define the function $\mathrm{f}^{\sigma}: \mathrm{T} \rightarrow \mathrm{R}$ by

$$
f^{\sigma}(t)=f(\sigma(t)) \text { for all } t \in T^{k}
$$

Fix $t \in T^{k}$ and let $f: T \rightarrow R$. Define $f^{\Delta}(t)$ to be the number (provided it exists) with theproperty that given any $\epsilon>0$, there is a neighborhood $U$ of $t$ such that $\left|\left[f^{\sigma}(t)-f(s)\right]-f^{\Delta}(t)[\sigma(t)-s]\right| \leq \epsilon|\sigma(t)-s|$ for all $\mathrm{s} \in \mathrm{U}$.In this case we say that $\mathrm{f}^{\Delta}(\mathrm{t})$ is the (delta) derivative of $\mathrm{f}$ at $\mathrm{t}$ and that $\mathrm{f}$ is (delta) differentiable at $\mathrm{t}$.

In limit form the (delta) derivative of a function $\mathrm{f}: \mathrm{T} \rightarrow \mathrm{R}$ is defined as

$$
\mathrm{f}^{\Delta}(\mathrm{t})= \begin{cases}\frac{\mathrm{f}(\sigma(\mathrm{t}))-\mathrm{f}(\mathrm{t})}{\mu(\mathrm{t})}, & \mu(\mathrm{t})>0 \\ \lim _{\mathrm{s} \rightarrow \mathrm{t}} \frac{\mathrm{f}(\mathrm{t})-\mathrm{f}(\mathrm{s})}{\mathrm{t}-\mathrm{s}}, & \mu(\mathrm{t})=0\end{cases}
$$

Wheret $\in \mathrm{T}^{\mathrm{k}}$ (provided that limit exists). Higher-order delta derivatives are defined recursively.

i.e. $\mathrm{f}^{\Delta^{\mathrm{n}}}=\left(\mathrm{f}^{\Delta^{\mathrm{n}-1}}\right)$ for $\mathrm{n} \in \mathrm{N}$ with the convention $\mathrm{f}^{\Delta^{0}}=\mathrm{f}$. Assume that $\mathrm{f}: \mathrm{T} \rightarrow \mathrm{R}$ andlet $\mathrm{t} \in \mathrm{T}^{\mathrm{k}}$, if $\mathrm{f}$ is (delta) differentiable at $t$, then $\mathrm{f}(\sigma(\mathrm{t}))=\mathrm{f}(\mathrm{t})+\mu(\mathrm{t}) \mathrm{f}^{\Delta}(\mathrm{t})$.

A functionF: $T \rightarrow R$ is called an anti-derivative of $f: T \rightarrow R$ provided $F^{\Delta}(t)=f(t)$ holds for all $t \in T^{k}$. It is well-known that every rd-continuous function has an anti-derivative. The set of functionsf: $\mathrm{T} \rightarrow \mathrm{R}$ that are n-times (delta) differentiable and whose nth order (delta) derivative is rd-continuous is denoted by $C_{\text {rd }}^{n}(T, R)$.

We will make use of the following product and quotient rules for the delta-derivatives of the product fg and $\frac{\mathrm{f}}{\mathrm{g}}\left(\right.$ wheregg $\left.^{\sigma} \neq 0, \mathrm{~g}^{\sigma}=\mathrm{go \sigma}\right)$ of two delta-differentiable functions $\mathrm{f}$ and $\mathrm{g}$ :

$$
(f g)^{\Delta}=f^{\Delta} g+f^{\sigma} g^{\Delta}=f g^{\Delta}+f^{\Delta} g^{\sigma}, \quad\left(\frac{f}{g}\right)^{\Delta}=\frac{f^{\Delta} g-g^{\Delta}}{g g^{\Delta}}
$$


Let $\mathrm{f}$ be a real-valued function defined on an interval $[\mathrm{a}, \mathrm{b}]_{\mathrm{T}}$. We say that $\mathrm{f}$ is increasing, decreasing, non-increasing, and non-decreasing on $[a, b]_{T}$ if for every $t_{1}, t_{2} \in[a, b]_{T}$ such thatt $t_{2}>t_{1}$ imply $f\left(t_{2}\right)>f\left(t_{1}\right)$, $\mathrm{f}\left(\mathrm{t}_{2}\right)<\mathrm{f}\left(\mathrm{t}_{1}\right), \mathrm{f}\left(\mathrm{t}_{2}\right) \leq \mathrm{f}\left(\mathrm{t}_{1}\right)$ and $\mathrm{f}\left(\mathrm{t}_{2}\right) \geq \mathrm{f}\left(\mathrm{t}_{1}\right)$ respectively. Let $\mathrm{f}$ be a differentiable function on[a,b] $]_{\mathrm{T}}$. Then $\mathrm{f}$ is increasing, decreasing, non-increasing and non-decreasing on $[a, b]_{T}$ iff $^{\Delta}(t)>0, f^{\Delta}(t)<0, f^{\Delta}(t) \leq 0$ and $f^{\Delta}(t) \geq$ Ofor all $\mathrm{t} \in[\mathrm{a}, \mathrm{b}]_{\mathrm{T}}$ respectively.

Theorem2.1. (Chain rule) ([1, Theorem 1.90]) Let $\mathrm{f}: \mathrm{R} \rightarrow \mathrm{R}$ is continuously differentiable and supposeg $: \mathrm{T} \rightarrow \mathrm{R}$ is delta differentiable. Then fog: $\mathrm{T} \rightarrow \mathrm{R}$ is delta differentiable and the formula

$$
(\text { fog })^{\Delta}(\mathrm{t})=\left\{\int_{0}^{1} \mathrm{f}^{\prime}\left(\mathrm{g}(\mathrm{t})+\mathrm{h} \mu(\mathrm{t}) \mathrm{g}^{\Delta}(\mathrm{t})\right) \mathrm{dh}\right\} \mathrm{g}^{\Delta}(\mathrm{t})
$$

Theorem2.2.([1, Theorem 1.117]).Let $\mathrm{a} \in \mathrm{T}^{\mathrm{k}}, \mathrm{b} \in \mathrm{T}$ and assume $\mathrm{f}: \mathrm{T} \times \mathrm{T}^{\mathrm{k}} \rightarrow$ Rcontinuous at $(\mathrm{t}, \mathrm{t})$, where $\mathrm{t} \in \mathrm{T}^{\mathrm{k}}$ with $\mathrm{t}>$ a. Also assume that $\mathrm{f}^{\Delta}(\mathrm{t}$, .) is rd-continuous on $[\mathrm{a}, \sigma(\mathrm{t})]$. Suppose that for each $\epsilon>0$ there exists a neighborhood $\mathrm{U}$ of $\mathrm{t}$, independent of $\tau \in[a, \sigma(t)]$, such that $\left|\left[\mathrm{f}^{\sigma}(\mathrm{t})-\mathrm{f}(\mathrm{s})\right]-\mathrm{f}^{\Delta}(\mathrm{t})[\sigma(\mathrm{t})-\mathrm{s}]\right| \leq \epsilon|\sigma(\mathrm{t})-\mathrm{s}|$ forall $\mathrm{s} \in \mathrm{U}$.Wheref ${ }^{\Delta}$ denotes the derivative of $\mathrm{f}$ with respect to the first variable. Then

$$
\begin{aligned}
& \text { (i) } g(t)=\int_{a}^{t} f(t, \tau) \Delta \operatorname{timpliesg}^{\Delta}(t)=\int_{a}^{t} f^{\Delta}(t, \tau) \Delta \tau+f(\sigma(t), t) \\
& \text { (ii) } h(t)=\int_{t}^{b} f(t, \tau) \Delta \operatorname{timpliesf~}^{\Delta}(t)=\int_{a}^{t} f^{\Delta}(t, \tau) \Delta \tau-f(\sigma(t), t)
\end{aligned}
$$

For more basic concepts in the time scale theory the readers are referred to the books (see[15, 16]).

\section{First, The existence of solutions of equation (1.1) in the class $\mathbf{M}^{+}$ \\ III. Existence And Non-Existence Of Solutions In $\mathrm{M}^{+}, \mathrm{M}^{-}$, OS And WOS}

Theorem3.1. With respect to the dynamic equation (1.1), assume that

(i) $\mathrm{p}(\mathrm{t}) \geq 0$ and non-decreasing for all $\mathrm{t} \in\left[\mathrm{t}_{0}, \infty\right)_{\mathrm{T}}$ and

(ii) $\lim \sup _{\mathrm{t} \rightarrow \infty} \int_{\mathrm{t}_{0}, \mathrm{t}}^{\mathrm{t}} \mathrm{q}(\mathrm{s}) \Delta \mathrm{s}=\infty$ hold.Then for equation (1.1), we have $\mathrm{M}^{+}=\emptyset$.

Proof.Suppose that the equation (1.1) has a solutionx $\in \mathrm{M}^{+}$. Without loss of generality, we may assume that $\mathrm{x}(\mathrm{t})>0$ and $\mathrm{x}^{\Delta}(\mathrm{t}) \geq 0$ for large $\mathrm{t} \in\left[\mathrm{t}_{0}, \infty\right)_{\mathrm{T}}$ (The proof is similar if $\mathrm{x}(\mathrm{t})<0$ and $\mathrm{x}^{\Delta}(\mathrm{t}) \leq 0$ for large $\left.\mathrm{t} \in\left[\mathrm{t}_{0}, \infty\right)_{\mathrm{T}}\right)$. Then there exists $t_{1} \in\left[t_{0}, \infty\right)_{T}$ such that $x(t), x(\alpha(t)), x(\beta(t))$ all are non-negative for all $t \in\left[t_{0}, \infty\right)_{T}$. Define $\mathrm{z}(\mathrm{t})=\mathrm{x}(\mathrm{t})+\mathrm{p}(\mathrm{t}) \mathrm{x}(\alpha(\mathrm{t}))(3.1)$

Fort $_{1} \in\left[\mathrm{t}_{0}, \infty\right)_{\mathrm{T}}$. Then by condition (i), we have $\mathrm{z}(\mathrm{t})>0$ and $\mathrm{z}^{\Delta}(\mathrm{t}) \geq 0$ for all $\mathrm{t} \in\left[\mathrm{t}_{1}, \infty\right)_{\mathrm{T}}$.Using (3.1), equation (1.1) becomes

$$
\begin{aligned}
& \left\{r(t) z^{\Delta}(t)\right\}^{\Delta}+q(t) f(x(\beta(t)))=0 \\
& \text { or } \\
& \left.\left\{\mathrm{r}(\mathrm{t}) \mathrm{z}^{\Delta}(\mathrm{t})\right\}^{\Delta}=-\mathrm{q}(\mathrm{t}) \mathrm{f}(\mathrm{x}(\beta(\mathrm{t}))) \text { fort } \in\left[\mathrm{t}_{1}, \infty\right)_{\mathrm{T}}\right)(3.2) \\
& \left(\frac{\mathrm{r}(\mathrm{t}) \mathrm{z}^{\Delta}(\mathrm{t})}{\mathrm{f}(\mathrm{x}(\beta(\mathrm{t})))}\right)^{\Delta}=\frac{\left\{\mathrm{r}(\mathrm{t}) \mathrm{z}^{\Delta}(\mathrm{t})\right\}^{\Delta}}{\mathrm{f}(\mathrm{x}(\beta(\mathrm{t})))}+\left(\mathrm{r}(\sigma(\mathrm{t})) \mathrm{z}^{\Delta}(\sigma(\mathrm{t}))\right)\left(\frac{1}{\mathrm{f}(\mathrm{x}(\beta(\mathrm{t})))}\right)^{\Delta} \\
& =\frac{\left\{\mathrm{r}(\mathrm{t}) \mathrm{z}^{\Delta}(\mathrm{t})\right\}^{\Delta}}{\mathrm{f}(\mathrm{x}(\beta(\mathrm{t})))}-\left(\mathrm{r}(\sigma(\mathrm{t})) \mathrm{z}^{\Delta}(\sigma(\mathrm{t}))\right)\left(\frac{(\mathrm{f}(\mathrm{x}(\beta(\mathrm{t}))))^{\Delta}}{\mathrm{f}^{\sigma}(\mathrm{x}(\beta(\mathrm{t}))) \mathrm{f}(\mathrm{x}(\beta(\mathrm{t})))}\right) \\
& =\frac{\left\{\mathrm{r}(\mathrm{t}) \mathrm{z}^{\Delta}(\mathrm{t})\right\}^{\Delta}}{\mathrm{f}(\mathrm{x}(\beta(\mathrm{t})))}-\left(\mathrm{r}(\sigma(\mathrm{t})) \mathrm{z}^{\Delta}(\sigma(\mathrm{t}))\right)\left(\frac{\left\{\int_{0}^{1} \mathrm{f}^{\prime}\left(\mathrm{x}\left(\beta(\mathrm{t})+\mathrm{h} \mu(\mathrm{t})(\mathrm{x}(\beta(\mathrm{t})))^{\Delta} \mathrm{dh}\right)\right)\right\}(\mathrm{x}(\beta(\mathrm{t})))^{\Delta}}{\mathrm{f}^{\sigma}(\mathrm{x}(\beta(\mathrm{t}))) \mathrm{f}(\mathrm{x}(\beta(\mathrm{t})))}\right) \\
& =\frac{\left\{\mathrm{r}(\mathrm{t}) \mathrm{z}^{\Delta}(\mathrm{t})\right\}^{\Delta}}{\mathrm{f}(\mathrm{x}(\beta(\mathrm{t})))}-\left(\mathrm{r}(\sigma(\mathrm{t})) \mathrm{z}^{\Delta}(\sigma(\mathrm{t}))\right)\left(\frac{\left\{\int_{0}^{1} \mathrm{f}^{\prime}\left(\mathrm{x}\left(\beta(\mathrm{t})+\mathrm{h} \mu(\mathrm{t})(\mathrm{x}(\beta(\mathrm{t})))^{\Delta} \mathrm{dh}\right)\right)\right\} \mathrm{x}^{\Delta}(\beta(\mathrm{t})) \beta^{\Delta}(\mathrm{t})}{\mathrm{f}^{\sigma}(\mathrm{x}(\beta(\mathrm{t}))) \mathrm{f}(\mathrm{x}(\beta(\mathrm{t})))}\right)(3.3)
\end{aligned}
$$

Therefore,

$$
\left(\frac{\left.\mathrm{r}(\mathrm{t}) \mathrm{z}^{\Delta}(\mathrm{t})\right)}{\mathrm{f}(\mathrm{x}(\beta(\mathrm{t})))}\right)^{\Delta} \leq \frac{\left\{\mathrm{r}(\mathrm{t}) \mathrm{z}^{\Delta}(\mathrm{t})\right\}^{\Delta}}{\mathrm{f}(\mathrm{x}(\beta(\mathrm{t})))}, \mathrm{t} \in\left[\mathrm{t}_{1}, \infty\right)_{\mathrm{T}}
$$

Because, $\mathrm{f}^{\prime}(\mathrm{u}) \geq 0$ for $\mathrm{u} \neq 0, \mathrm{z}^{\Delta}(\mathrm{t}) \geq 0 \operatorname{andx}^{\Delta}(\beta(\mathrm{t})) \geq 0 \forall \mathrm{t} \in\left[\mathrm{t}_{1}, \infty\right)_{\mathrm{T}}$

From (3.2) and (3.4),we have

$$
\left(\frac{\mathrm{r}(\mathrm{t}) \mathrm{z}^{\Delta}(\mathrm{t})}{\mathrm{f}(\mathrm{x}(\beta(\mathrm{t})))}\right)^{\Delta} \leq-\mathrm{q}(\mathrm{t}) \text { for } \mathrm{t} \in\left[\mathrm{t}_{1}, \infty\right)_{\mathrm{T}}
$$

Integrating the last inequality from $t_{1}$ to $t$, we obtain

From given condition (ii), we obtain

$$
\frac{r(t) z^{\Delta}(t)}{f(x(\beta(t)))}-\frac{r\left(t_{1}\right) z^{\Delta}\left(t_{1}\right)}{f\left(x\left(\beta\left(t_{1}\right)\right)\right)} \leq-\int_{t_{1}}^{t} q(s) \Delta s
$$




$$
\liminf _{t \rightarrow \infty} \frac{r(t) z^{\Delta}(t)}{f(x(\beta(t)))}=-\infty,
$$

Which contradicts the assumptionz $z^{\Delta}(t) \geq 0$ for large $t$. Thus, the theorem is proved.

Example3.2. In Theorem 3.1, the assumption (ii) cannot be dropped. For this, suppose $\mathrm{T}=\mathrm{q}^{\mathrm{N}_{0}}$, where $\mathrm{q}>1$ is a fixed real number and consider the following q- difference equation

$$
\Delta_{\mathrm{q}}\left[1 / \mathrm{t}^{2} \Delta_{\mathrm{q}}\left(\mathrm{x}(\mathrm{t})+\mathrm{q}\left(1-\frac{1}{\mathrm{t}}\right) \mathrm{x}(\mathrm{t} / \mathrm{q})\right)\right]+\frac{2 \mathrm{q}^{\frac{2}{3}}\left(1-1 / \mathrm{q}^{2}\right)}{\mathrm{q}-1} \frac{1}{\mathrm{t}^{\frac{10}{3}}} \mathrm{x}^{\frac{1}{3}}\left(\frac{\mathrm{t}}{\mathrm{q}^{2}}\right)=0, \mathrm{t} \in \mathrm{T}(3.5)
$$

For this q- difference equation, assumption (i) holds, but (ii) is violated. The equation (3.5) has a solution $\mathrm{x}(\mathrm{t})=\mathrm{t} \in \mathrm{M}^{+}$.

Theorem3.3. With respect to the dynamic equation (1.1), assume that

(iii) $-1<p(\mathrm{t}) \leq 0$ for all $\mathrm{t} \in\left[\mathrm{t}_{0}, \infty\right)_{\mathrm{T}}$;

(iv) $\mathrm{q}(\mathrm{t}) \geq 0$ for all $\mathrm{t} \in\left[\mathrm{t}_{0}, \infty\right)_{\mathrm{T}}$;

(v) $\lim _{\mathrm{t} \rightarrow \infty} \int_{\mathrm{t}_{0}}^{\mathrm{t}} \mathrm{q}(\mathrm{s}) \Delta \mathrm{s}=\infty$; and

(vi) $\lim _{\mathrm{t} \rightarrow \infty} \int_{\mathrm{t}_{0}}^{\mathrm{t}} \frac{1}{\mathrm{r}(\mathrm{s})} \Delta \mathrm{s}=\infty$ hold. Then for equation (1.1), we haveM ${ }^{+}=\emptyset$.

Proof.Suppose that the equation (1.1) has a solution $\mathrm{x} \in \mathrm{M}^{+}$. Proceeding as in the proof of Theorem3.1, we have (3.1) and (3.2). Since $x \in M^{+}$and (iii), we have

$$
\mathrm{z}(\mathrm{t})=\mathrm{x}(\mathrm{t})+\mathrm{p}(\mathrm{t}) \mathrm{x}(\alpha(\mathrm{t})) \geq \mathrm{x}(\alpha(\mathrm{t}))+\mathrm{p}(\mathrm{t}) \mathrm{x}(\alpha(\mathrm{t}))=(1+\mathrm{p}(\mathrm{t})) \mathrm{x}(\alpha(\mathrm{t}))>0
$$

For $\mathrm{t} \in\left[\mathrm{t}_{1}, \infty\right)_{\mathrm{T}}$. From (3.1) and (iv), (1.1) becomes

$$
\left\{r(t) z^{\Delta}(t)\right\}^{\Delta}=-q(t) f(x(\beta(t))) \leq 0, \quad \text { for } t \in\left[t_{1}, \infty\right)_{T}
$$

This implies that $r(t) z^{\Delta}(t)$ is non increasing ont $\in\left[t_{1}, \infty\right)_{T}$. Now suppose that $r(t) z^{\Delta}(t)<0$ for large $t \in\left[t_{1}, \infty\right)_{T}$. Then there exists $t_{2} \in\left[t_{1}, \infty\right)_{T}$ such that

$$
\begin{aligned}
r(t) z^{\Delta}(t) & \leq r\left(t_{2}\right) z^{\Delta}\left(t_{2}\right)<0 \\
z^{\Delta}(t) & \leq \frac{r\left(t_{2}\right) z^{\Delta}\left(t_{2}\right)}{r(t)}
\end{aligned}
$$

Integrating from $t_{2}$ to $t$, we obtain

$$
z(t)-z\left(t_{2}\right) \leq \int_{t_{2}}^{t} \frac{r\left(t_{2}\right) z^{\Delta}\left(t_{2}\right)}{r(s)} \Delta s
$$

This implies that $\mathrm{z}(\mathrm{t}) \rightarrow-\infty$ as $\mathrm{t} \rightarrow \infty$ due to (vi), which is a contradiction.

Thus, $r(t) z^{\Delta}(t) \geq 0$ for large $t \in\left[t_{1}, \infty\right)_{T}$.

Hence,

$$
z^{\Delta}(t) \geq 0
$$

Now proceeding as in the proof of Theorem 3.1, we obtain

$$
\lim _{t \rightarrow \infty} \frac{r(t) z^{\Delta}(t)}{f(x(\beta(t)))}=-\infty,
$$

due to (v), which contradicts the assumption $z^{\Delta}(t) \geq 0$ for large $t \in\left[t_{1}, \infty\right)_{T}$.

This completes the proof of the theorem.

Example3.4. In theorem 3.3, some of the assumptions cannot be dropped. For this, suppose $\mathrm{T}=\mathrm{Z}$ and the difference equation

$\Delta\left\{\mathrm{e}^{-\mathrm{n}} \Delta\left(\mathrm{x}(\mathrm{n})-\mathrm{e}^{-3 \mathrm{n}+2} \mathrm{x}(\mathrm{n}-2)\right)\right\}+\left(\mathrm{e}^{-2}-1\right)\left(\mathrm{e}^{-3}-1\right) \mathrm{e}^{9} \mathrm{e}^{-6 \mathrm{n}} \mathrm{x}^{3}(\mathrm{n}-3)=0, \mathrm{n}(\geq 3) \in \mathrm{T}$. (3.6)

For this difference equation conditions (iii), (iv) and (vi) are satisfied, whereas, (v) is violated. The equation (3.6) has a solution $\mathrm{x}(\mathrm{n})=\mathrm{e}^{\mathrm{n}} \in \mathrm{M}^{+}$

\section{Next, The existence of solutions of equation(1.1) in the class $\mathrm{M}^{-}$:}

Theorem3.5. With respect to the dynamic equation (1.1), assume that

(vii) $\beta(\mathrm{t}) \leq \alpha(\mathrm{t})$;

(viii)the function $\frac{1}{\mathrm{f}(\mathrm{u})}$ is locally integrableon $(0, \mathrm{c})$ and $(-\mathrm{c}, 0)$ for some $\mathrm{c}>0$,

i.e $\int_{0}^{c} \frac{d u}{f(u)}<\infty, \quad \int_{-c}^{0} \frac{d u}{f(u)}>\infty$; forsome $c>0$

(ix)f is sub multiplicative i.e.f(uv) $\leq \mathrm{f}(\mathrm{u}) \mathrm{f}(\mathrm{v})$ for $\mathrm{u}, \mathrm{v} \in \mathrm{R}$;

(x) $\mathrm{p}(\mathrm{t}) \geq 0$ and non-increasing; and

(xi) $\lim \sup _{\mathrm{t} \rightarrow \infty} \int_{\mathrm{t}_{0}}^{\mathrm{t}} \frac{1}{\mathrm{r}(\mathrm{s}) \mathrm{f}(1+\mathrm{p}(\mathrm{s}))} \int_{\mathrm{t}_{0}}^{\mathrm{s}} \mathrm{q}(\tau) \Delta \tau \Delta \mathrm{s}=$ ohold. 
Then for equation (1.1), we have $\mathrm{M}^{-}=\varnothing$.

Proof.Suppose that equation (1.1) has a solution $\mathrm{x} \in \mathrm{M}^{-}$. Without loss of generality, we may assume that $x(t)>0$ and $x^{\Delta}(t) \leq 0$ for large $t \in\left[t_{0}, \infty\right)_{T}$. Then there exists $t_{1} \in\left[t_{0}, \infty\right)_{T}$ such thatx $(t), x(\alpha(t)), x(\beta(t))$ all are positive and $x^{\Delta}(t), x^{\Delta}(\alpha(t)), x^{\Delta}(\beta(t))$ all are non-positive for all $t \in\left[t_{1}, \infty\right)_{T}$. Defining $z(t)$ as in (3.1). Then by using $(\mathrm{x})$, we see that $\mathrm{z}(\mathrm{t})>0$ and $\mathrm{z}^{\Delta}(\mathrm{t}) \leq 0$ for all $\mathrm{t} \in\left[\mathrm{t}_{1}, \infty\right)_{T}$. Then equation (1.1) becomes

$$
\left\{r(t) z^{\Delta}(t)\right\}^{\Delta}+q(t) f(x(\beta(t)))=0 \text { for } t \in\left[t_{1}, \infty\right)_{T} .
$$

proceeding as in the proof of theorem (3.1), we obtain

$$
\frac{r(t) z^{\Delta}(t)}{f(x(\beta(t)))}-\frac{r\left(t_{1}\right) z^{\Delta}\left(t_{1}\right)}{f\left(x\left(\beta\left(t_{1}\right)\right)\right)} \leq-\int_{t_{1}}^{t} q(s) \Delta s
$$

Which implies that,

$\frac{z^{\Delta}(t)}{\mathrm{f}(\mathrm{x}(\beta(\mathrm{t})))} \leq-\frac{1}{\mathrm{r}(\mathrm{t})} \int_{\mathrm{t}_{1}}^{\mathrm{t}} \mathrm{q}(\mathrm{s}) \Delta \mathrm{s}$

Since, $x$ is non-increasing and $\beta(t) \leq \alpha(t)$ then we have

have

$$
\mathrm{z}(\mathrm{t})=\mathrm{x}(\mathrm{t})+\mathrm{p}(\mathrm{t}) \mathrm{x}(\alpha(\mathrm{t})) \leq(1+\mathrm{p}(\mathrm{t})) \mathrm{x}(\alpha(\mathrm{t})) \leq(1+\mathrm{p}(\mathrm{t})) \mathrm{x}(\beta(\mathrm{t})) \text { for } \mathrm{t} \in\left[\mathrm{t}_{1}, \infty\right)_{T} \text {. Using (ix), we }
$$

$$
f(z(t)) \leq f((1+p(t))) f(x(\beta(t))) \text { for } t \in\left[t_{1}, \infty\right)_{T} .
$$

From (3.7) and (3.8), we have

$$
\frac{z^{\Delta}(t) f((1+p(t)))}{f(z(t))} \leq-\frac{1}{r(t)} \int_{t_{1}}^{t} q(\tau) \Delta \tau,
$$

Implies that

$$
\frac{z^{\Delta}(t)}{f(z(t))} \leq-\frac{1}{r(t) f((1+p(t)))} \int_{t_{1}}^{t} q(\tau) \Delta \tau
$$

Integrating the last inequality from $t_{1}$ to $t$, we obtain

Implies that,

$$
\int_{t_{1}}^{t} \frac{z^{\Delta}(t)}{f(z(t))} \Delta t \leq-\int_{t_{1}}^{t} \frac{1}{r(s) f((1+p(s)))} \int_{t_{1}}^{s} q(\tau) \Delta \tau \Delta s
$$

$$
\begin{gathered}
\int_{z\left(t_{1}\right)}^{z(t)}-\frac{1}{f(u)} \Delta u \geq \int_{t_{1}}^{t} \frac{1}{r(s) f((1+p(s)))} \int_{t_{1}}^{s} q(\tau) \Delta \tau \Delta s \\
\int_{z(t)}^{z\left(t_{1}\right)} \frac{1}{f(u)} d u \geq \int_{z\left(t_{1}\right)}^{z(t)}-\frac{1}{f(u)} \Delta u \geq \int_{t_{1}}^{t} \frac{1}{r(s) f((1+p(s)))} \int_{t_{1}}^{s} q(\tau) \Delta \tau \Delta s
\end{gathered}
$$

Using (xi), we have

$$
\limsup _{\mathrm{t} \rightarrow \infty} \int_{z(\mathrm{t})}^{\mathrm{z}\left(\mathrm{t}_{1}\right)} \frac{1}{\mathrm{f}(\mathrm{u})} \Delta \mathrm{u}=\infty,
$$

Which contradicts to(viii).This completes the proof of the theorem.

Example 3.6. In theorem 3.5, some of the assumptions cannot be dropped. For this, suppose $T=R$ and the differential equation

$$
\left\{t^{2}(x(t)+(1-1 / t) x(t / 3))^{\prime}\right\}^{\prime}+\frac{2}{t^{5 / 3}} x^{1 / 3}\left(\frac{t}{27}\right)=0, \quad t \in\left[t_{0}, \infty\right)_{T}, t_{0}>0 .(3.9)
$$

For the equation (3.9), all assumptions of Theorem 3.5 are hold, except(x) and (xi).The equation (3.9) has a solution $x(t)=\frac{1}{t} \in M^{-}$

Theorem3.7.With respect to the dynamic equation (1.1), assume that (vi), (x) and

(xii) $\mathrm{q}(\mathrm{t})>0$ for large $\mathrm{t} \in\left[\mathrm{t}_{0}, \infty\right)_{\mathrm{T}}$ hold. Then for equation (1.1), we haveM ${ }^{-}=\varnothing$.

Proof. Proceeding as in the proof of Theorem 3.5, we have

$$
\left\{\mathrm{r}(\mathrm{t}) \mathrm{z}^{\Delta}(\mathrm{t})\right\}^{\Delta}=-\mathrm{q}(\mathrm{t}) \mathrm{f}(\mathrm{x}(\beta(\mathrm{t})))<0 \text { for } \mathrm{t} \in\left[\mathrm{t}_{1}, \infty\right)_{\mathrm{T}} .
$$

Then $r(t) z^{\Delta}(t)$ is decreasing. For $t>t_{1}$, we have

$$
\begin{aligned}
r(t) z^{\Delta}(t) & <r\left(t_{1}\right) z^{\Delta}\left(t_{1}\right)<0, \\
& \text { Or } \\
\mathrm{z}^{\Delta}(\mathrm{t}) & <r\left(\mathrm{t}_{1}\right) \mathrm{z}^{\Delta}\left(\mathrm{t}_{1}\right) \frac{1}{\mathrm{r}(\mathrm{t})}
\end{aligned}
$$

Integrating from $t_{1}$ to tand using (vi), we get 


$$
z(t) \leq z\left(t_{1}\right)+r\left(t_{1}\right) z^{\Delta}\left(t_{1}\right) \int_{t_{1}}^{t} \frac{1}{r(s)} \Delta s .
$$

This implies that, $\mathrm{z}(\mathrm{t}) \rightarrow-\infty$ as $\mathrm{t} \rightarrow \infty$, whichcontradicts to our assumption that $\mathrm{z}(\mathrm{t})>0$ for all $t \in\left[t_{1}, \infty\right)_{T}$. This complete the proof of the theorem.

Theorem3.8. With respect to the dynamic equation(1.1), assume that (iii),(v),(vi) and (xii) holds. Then for equation (1.1), we have $\mathrm{M}^{-}=\emptyset$.

Proof. Suppose that equation (1.1) has a solutionx $\in \mathrm{M}^{-}$. Proceeding as in the proof of Theorem 3.5 , We have (3.1) and (3.2). Since $x \in M^{-}$and (iii), we have

From (3.2) and (xii), we have

$$
\mathrm{z}(\mathrm{t})=\mathrm{x}(\mathrm{t})+\mathrm{p}(\mathrm{t}) \mathrm{x}(\alpha(\mathrm{t})) \geq \mathrm{x}(\mathrm{t})+\mathrm{p}(\mathrm{t}) \mathrm{x}(\mathrm{t}) \geq(1+\mathrm{p}(\mathrm{t})) \mathrm{x}(\mathrm{t})>0
$$

$$
\left\{\mathrm{r}(\mathrm{t}) \mathrm{z}^{\Delta}(\mathrm{t})\right\}^{\Delta}=-\mathrm{q}(\mathrm{t}) \mathrm{f}(\mathrm{x}(\beta(\mathrm{t})))<0 \text { fort } \in\left[\mathrm{t}_{1}, \infty\right)_{\mathrm{T}} .
$$

It follows that, $r(t) z^{\Delta}(t)$ is decreasing fort $\in\left[t_{1}, \infty\right)_{T}$. Now proceeding as in the proof of Theorem 3.3. In view of $(v i)$, we findr $(t) z^{\Delta}(t) \geq 0$ for $t \in\left[t_{1}, \infty\right)_{T}$. Then

We define, $\quad w(t)=\frac{r(t) z^{\Delta}(t)}{f(z(t))}$ fort $\in\left[t_{1}, \infty\right)_{T}$.

$$
\begin{gathered}
w^{\Delta}(\mathrm{t})=\frac{\left\{\mathrm{r}(\mathrm{t}) \mathrm{z}^{\Delta}(\mathrm{t})\right\}^{\Delta}}{\mathrm{f}(\mathrm{z}(\beta(\mathrm{t})))}+\left(\mathrm{r}(\sigma(\mathrm{t})) \mathrm{z}^{\Delta}(\sigma(\mathrm{t}))\right)\left(\frac{1}{\mathrm{f}(\mathrm{z}(\beta(\mathrm{t})))}\right)^{\Delta} \\
=\frac{\left\{\mathrm{r}(\mathrm{t}) \mathrm{z}^{\Delta}(\mathrm{t})\right\}^{\Delta}}{\mathrm{f}(\mathrm{z}(\beta(\mathrm{t})))}-\left(\mathrm{r}(\sigma(\mathrm{t})) \mathrm{z}^{\Delta}(\sigma(\mathrm{t}))\right)\left(\frac{(\mathrm{f}(\mathrm{x}(\beta(\mathrm{t}))))^{\Delta}}{\mathrm{f}^{\sigma}(\mathrm{z}(\beta(\mathrm{t}))) \mathrm{f}(\mathrm{z}(\beta(\mathrm{t})))}\right) \\
=\frac{\left\{\mathrm{r}(\mathrm{t}) \mathrm{z}^{\Delta}(\mathrm{t})\right\}^{\Delta}}{\mathrm{f}(\mathrm{z}(\beta(\mathrm{t})))}-\left(\mathrm{r}(\sigma(\mathrm{t})) \mathrm{z}^{\Delta}(\sigma(\mathrm{t}))\right)\left(\frac{\left.\left\{\int_{0}^{1} \mathrm{f}^{\prime}\left(\mathrm{x}(\beta(\mathrm{t})+\mathrm{h} \mu(\mathrm{t})(\mathrm{x}(\beta(\mathrm{t}))))^{\Delta} \mathrm{dh}\right)\right)\right\}(\mathrm{x}(\beta(\mathrm{t})))^{\Delta}}{\mathrm{f}^{\sigma}(\mathrm{z}(\beta(\mathrm{t}))) \mathrm{f}(\mathrm{z}(\beta(\mathrm{t})))}\right) \\
=\frac{\left\{\mathrm{r}(\mathrm{t}) \mathrm{z}^{\Delta}(\mathrm{t})\right\}^{\Delta}}{\mathrm{f}(\mathrm{x}(\beta(\mathrm{t})))}-\left(\mathrm{r}(\sigma(\mathrm{t})) \mathrm{z}^{\Delta}(\sigma(\mathrm{t}))\right)\left(\frac{\left.\left\{\int_{0}^{1} \mathrm{f}^{\prime}\left(\mathrm{x}(\beta(\mathrm{t})+\mathrm{h} \mu(\mathrm{t})(\mathrm{x}(\beta(\mathrm{t}))))^{\Delta} \mathrm{dh}\right)\right)\right\} \mathrm{x}^{\Delta}(\beta(\mathrm{t})) \beta^{\Delta}(\mathrm{t})}{\mathrm{f}^{\sigma}(\mathrm{x}(\beta(\mathrm{t}))) \mathrm{f}(\mathrm{x}(\beta(\mathrm{t})))}\right)
\end{gathered}
$$

Therefore,

$$
w^{\Delta}(t) \leq-q(t) \frac{f(x(\beta(t)))}{f(z(\beta(t)))} \text { fort } \in\left[t_{1}, \infty\right)_{T}
$$

In view of (iii), we have $\mathrm{z}(\mathrm{t}) \leq \mathrm{x}(\mathrm{t})$ for $\mathrm{t} \in\left[\mathrm{t}_{1}, \infty\right)_{\mathrm{T}}$. Using this inequality in (3.10) andintegrating the resulting inequality, we get

$\mathrm{w}(\mathrm{t}) \leq \mathrm{w}\left(\mathrm{t}_{1}\right)-\int_{\mathrm{t}_{1}}^{\mathrm{t}} \mathrm{q}(\mathrm{s}) \Delta \mathrm{s}$,

Which implies,

$w(t) \rightarrow-\infty$ as $t \rightarrow \infty$, due to (v) which is contradiction. This complete the proof.

Next we establish sufficient conditions under which equation(1.1)has no weakly oscillatory solutions.

Theorem3.9. With respect to the dynamic equation(1.1), assume that (iv) and $\alpha(t)=t$ hold. If (xiii) $p(t) \equiv$ $\mathrm{p}(\geq 0)$ for $\mathrm{t} \in\left[\mathrm{t}_{0}, \infty\right)_{\mathrm{T}}$ then for equation (1.1), we have $\mathrm{WOS}=\varnothing$.

Proof. Let $\mathrm{x}$ be a weakly oscillatory solution of (1.1). Without loss of generality, we may assume that $\mathrm{x}(\mathrm{t})>$ Ofor large $t \in\left[\mathrm{t}_{0}, \infty\right)_{\mathrm{T}}$ (the proof is similar if $\mathrm{x}(\mathrm{t})<0$ for large $t \in\left[\mathrm{t}_{0}, \infty\right)_{\mathrm{T}}$ ). Then there existst $t_{1} \in\left[\mathrm{t}_{0}, \infty\right)_{\mathrm{T}}$ such that $\mathrm{x}(\mathrm{t}), \mathrm{x}(\alpha(\mathrm{t})), \mathrm{x}(\beta(\mathrm{t}))$ all are positive for all $\mathrm{t} \in\left[\mathrm{t}_{1}, \infty\right)_{\mathrm{T}}$. Define $\mathrm{z}(\mathrm{t})$ as in Theorem (3.1), then by using (xiii), we see that $\mathrm{z}(\mathrm{t})>0$ for $t \in\left[\mathrm{t}_{1}, \infty\right)_{\mathrm{T}}$ and $\mathrm{z}^{\Delta}(\mathrm{t})$ oscillatesfor large t. From equation (3.1) and (iv), equation (1.1) becomes

$$
\left\{r(t) z^{\Delta}(t)\right\}^{\Delta}=-q(t) f(x(\beta(t))) \leq 0 \text { fort } \in\left[t_{1}, \infty\right)_{T} .
$$

By taking $F(t)=r(t) z^{\Delta}(t)$, then above equation reduces to

$$
\mathrm{F}(\mathrm{t})^{\Delta}=-\mathrm{q}(\mathrm{t}) \mathrm{f}(\mathrm{x}(\beta(\mathrm{t}))) \leq 0 \text { for } \mathrm{t} \in\left[\mathrm{t}_{1}, \infty\right)_{\mathrm{T}} .
$$

This implies that $\mathrm{F}$ is non-increasing, which gives a contradiction, because $\mathrm{F}$ is an oscillatory function. This completes the proof of the theorem.

Example3.10.In Theorem 3.9, the assumption (iv) cannot be dropped. For this, suppose $\mathrm{T}=\mathrm{q}^{\mathrm{N}_{0}}$, where $\mathrm{q}>1$ is a fixed real number and consider the following q-difference equation

$$
\Delta_{\mathrm{q}}\left(\mathrm{t} \Delta_{\mathrm{q}}(\mathrm{x}(\mathrm{t})+2 \mathrm{x}(\mathrm{t}))\right)+\frac{12}{(\mathrm{q}-1)^{2}} \frac{(-1)^{\log _{\mathrm{q}}^{\mathrm{qt}}}}{\mathrm{t}\left(2-(-1)^{\log _{\mathrm{q}}}\right)^{3}} \mathrm{x}^{3}\left(\frac{\mathrm{t}}{\mathrm{q}}\right)=0, \mathrm{t} \in \mathrm{T}
$$

For this q-difference equation, all assumptions of Theorem 3.9 hold, but (iv) is violated. The equation (3.12) has a solution $2+(-1)^{\log _{\mathrm{q}}^{t}}$ belongs to WOS. 
The following theorem holds when $\mathrm{T}=\mathrm{R}$, but not on arbitrary time scale.

Theorem3.11. With respect to the dynamic equation(1.1), assume that $(v)$, and (xiii). If $\alpha(t)=t=\beta(t)$ then for equation (1.1), we haveWOS $=\emptyset$.

Proof. Let $\mathrm{x}$ be a weakly oscillatory solution of (1.1). Without loss of generality, we may assume that $x(t)>$ 0for large $t \in\left[t_{0}, \infty\right)_{T}$ (the proof is similar if $x(t)<0$ for large $t \in\left[t_{0}, \infty\right)_{T}$ ). Then there exists $t_{1} \in\left[t_{0}, \infty\right)_{T}$ such that $x(t), x(\alpha(t)), x(\beta(t))$ all are positive for all $t \in\left[t_{1}, \infty\right)_{T}$. Define $z(t)$ as in Theorem (3.1). Then by using (xiii), we see that $\mathrm{z}(\mathrm{t})=(1+\mathrm{p}(\mathrm{t})) \mathrm{x}(\mathrm{t})>0$ for $\mathrm{t} \in\left[\mathrm{t}_{1}, \infty\right)_{\mathrm{T}}$ and $\mathrm{z}^{\Delta}(\mathrm{t})=(1+\mathrm{p}) \mathrm{x}^{\Delta}(\mathrm{t})$ oscillates for large t. Using (3.1), equation (1.1) becomes

$$
\left\{r(t) z^{\Delta}(t)\right\}^{\Delta}=-q(t) f(x(t)) \text { for } t \in\left[t_{1}, \infty\right)_{T} .
$$

Now for $t \in\left[t_{1}, \infty\right)_{T}$, Now for $t \in\left[t_{0}, \infty\right)_{T}$, we obtain

$$
\begin{gathered}
\left(\frac{\mathrm{r}(\mathrm{t}) \mathrm{z}^{\Delta}(\mathrm{t})}{\mathrm{f}(\mathrm{x}((\mathrm{t})))}\right)^{\Delta}=\frac{\left\{\mathrm{r}(\mathrm{t}) \mathrm{z}^{\Delta}(\mathrm{t})\right\}^{\Delta}}{\mathrm{f}(\mathrm{x}((\mathrm{t})))}+\left(\mathrm{r}(\mathrm{t})(1+\mathrm{p}) \mathrm{x}^{\Delta}(\mathrm{t})\right)\left(\frac{1}{\mathrm{f}(\mathrm{x}((\mathrm{t})))}\right)^{\Delta} \\
=\frac{\left\{\mathrm{r}(\mathrm{t}) \mathrm{z}^{\Delta}(\mathrm{t})\right\}^{\Delta}}{\mathrm{f}(\mathrm{x}(\mathrm{t}))}-\mathrm{r}(\mathrm{t})(1+\mathrm{p}) \mathrm{x}^{\Delta}(\mathrm{t})\left(\frac{\left(\mathrm{f}(\mathrm{x}(\mathrm{t}))^{\Delta}\right.}{\left.\left.\mathrm{f}^{\sigma}(\mathrm{x}(\mathrm{t}))\right) \mathrm{f}(\mathrm{x}(\mathrm{t}))\right)}\right)
\end{gathered}
$$

Since $\mathrm{T}=\mathrm{R}$, the equation (3.13)becomes

Therefore,

$$
\begin{gathered}
\left(\frac{r(t) z^{\prime}(t)}{f(x((t)))}\right)^{\prime}=\frac{\left\{r(t) z^{\prime}(t)\right\}^{\prime}}{f(x(t))}-r(t)(1+p) x^{\prime}(t)\left(\frac{(f(x)(t))^{\prime}}{f^{\sigma}(x(t)) f(x(t))}\right) \\
=\frac{\left\{r(t) z^{\prime}(t)\right\}^{\prime}}{f(x(t))}-r(t)(1+p)\left(x^{\prime}(t)\right)^{2}\left(\frac{f^{\prime}(x(t))}{f^{2}(x(t))}\right)
\end{gathered}
$$

$$
\begin{aligned}
& \left(\frac{\mathrm{r}(\mathrm{t}) \mathrm{z}^{\prime}(\mathrm{t})}{\mathrm{f}(\mathrm{x}(\mathrm{t}))}\right)^{\prime} \leq \frac{\left\{\mathrm{r}(\mathrm{t}) \mathrm{z}^{\prime}(\mathrm{t})\right\}^{\prime}}{\mathrm{f}(\mathrm{x}(\mathrm{t}))} \\
\leq & -\mathrm{q}(\mathrm{t}) \quad \text { for all } \mathrm{t} \in\left[\mathrm{t}_{1}, \infty\right)_{\mathrm{T}}
\end{aligned}
$$

Integrating the from $t_{1}$ to $t$, we obtain

$$
\left(\frac{r(t) z^{\prime}(t)}{f(x(t))}\right)-\left(\frac{r\left(t_{1}\right) z^{\prime}\left(t_{1}\right)}{f(x(t))}\right) \leq-\int_{t_{1}}^{t} q(s) \Delta s
$$

From(v), for large $t \in\left[t_{1}, \infty\right)_{T}$, we obtain $z^{\prime}(t)<0$, Whichis contradiction, because $x$ is weakly oscillatory. Theorem3.12. Withrespect to dynamic equation(1.1), assume that (iv), (v),(vi) and (xiii) hold. If

(xiv) $\mathrm{p}(\mathrm{t}) \equiv \mathrm{p}(\geq 0)$ for $\mathrm{t} \in\left[\mathrm{t}_{0}, \infty\right)_{\mathrm{T}}$. Then every solution of equation(1.1) is either oscillatory or weakly oscillatory.

Proof. From Theorem 3.1, it follows that for equation (1.1) the class $\mathrm{M}^{+}=\varnothing$.In order to complete the proof of it suffices to show that $\mathrm{M}^{-}=\emptyset$.Suppose that equation (1.1) has a solution $\mathrm{x} \in \mathrm{M}^{-}$. Without loss of generality, we may assume that $\mathrm{x}(\mathrm{t})>0$ and $\mathrm{x}^{\Delta}(\mathrm{t}) \leq 0$ for large $\mathrm{t} \in\left[\mathrm{t}_{0}, \infty\right)_{\mathrm{T}}$ (the proof is similar if $\mathrm{x}(\mathrm{t})<0$ and $\mathrm{x}^{\Delta}(\mathrm{t}) \geq 0$ for large $\left.t \in\left[t_{0}, \infty\right)_{T}\right)$. Then there exists $t_{1} \in\left[t_{0}, \infty\right)_{T}$ such that $x(t), x(\alpha(t)), x(\beta(t))$ all are positive and $x^{\Delta}(t)$, $\mathrm{x}^{\Delta}(\alpha(\mathrm{t})), \mathrm{x}^{\Delta}(\beta(\mathrm{t}))$ all are non-positive for all $\mathrm{t} \in\left[\mathrm{t}_{1}, \infty\right)_{\mathrm{T}}$. Defining $\mathrm{z}(\mathrm{t})$ as in (3.1). Then by using (xiv), we $\operatorname{seez}(\mathrm{t})>0$ andz $^{\Delta}(\mathrm{t}) \leq 0$ for all $\mathrm{t} \in\left[\mathrm{t}_{1}, \infty\right)_{\mathrm{T}}$. Then from equation (3.1), (1.1) reduces to

$$
\left\{\mathrm{r}(\mathrm{t}) \mathrm{z}^{\Delta}(\mathrm{t})\right\}^{\Delta}=-\mathrm{q}(\mathrm{t}) \mathrm{f}(\mathrm{x}(\beta(\mathrm{t}))) \leq 0 \text { fort } \in\left[\mathrm{t}_{1}, \infty\right)_{\mathrm{T}} .
$$

Now for $t>t_{2} \geq t_{1}\left(t_{2} \in\left[t_{1}, \infty\right)_{T}\right)$, we have

$$
\begin{gathered}
\left(\frac{\mathrm{r}(\mathrm{t}) \mathrm{z}^{\Delta}(\mathrm{t})}{\mathrm{f}(\mathrm{x}(\beta(\mathrm{t})))}\right)^{\Delta}=\frac{\left\{\mathrm{r}(\mathrm{t}) \mathrm{z}^{\Delta}(\mathrm{t})\right\}^{\Delta}}{\mathrm{f}(\mathrm{x}(\beta(\mathrm{t})))}+\left(\mathrm{r}(\sigma(\mathrm{t})) \mathrm{z}^{\Delta}(\sigma(\mathrm{t}))\right)\left(\frac{1}{\mathrm{f}(\mathrm{x}(\beta(\mathrm{t})))}\right)^{\Delta} \\
=-\mathrm{q}(\mathrm{t})+\left(\mathrm{r}(\sigma(\mathrm{t})) \mathrm{z}^{\Delta}(\sigma(\mathrm{t}))\right)\left(\frac{1}{\mathrm{f}(\mathrm{x}(\beta(\mathrm{t})))}\right)^{\Delta} \\
\leq\left(\mathrm{r}(\sigma(\mathrm{t})) \mathrm{z}^{\Delta}(\sigma(\mathrm{t}))\right)\left(\frac{1}{\mathrm{f}(\mathrm{x}(\beta(\mathrm{t})))}\right)^{\Delta}
\end{gathered}
$$

Integrating the fromt ${ }_{2}$ to $t$, we obtain 


$$
\begin{aligned}
\left(\frac{\mathrm{r}(\mathrm{t}) \mathrm{z}^{\Delta}(\mathrm{t})}{\mathrm{f}(\mathrm{x}(\beta(\mathrm{t})))}\right) & -\left(\frac{\mathrm{r}\left(\mathrm{t}_{2}\right) \mathrm{z}^{\Delta}\left(\mathrm{t}_{2}\right)}{\mathrm{f}\left(\mathrm{x}\left(\beta\left(\mathrm{t}_{2}\right)\right)\right)}\right) \leq \int_{\mathrm{t}_{2}}^{\mathrm{t}}\left(\mathrm{r}(\sigma(\mathrm{s})) \mathrm{z}^{\Delta}(\sigma(\mathrm{s}))\right)\left(\frac{1}{\mathrm{f}(\mathrm{x}(\beta(\mathrm{s})))}\right)^{\Delta} \Delta s \\
& \leq\left(\mathrm{r}\left(\sigma\left(\mathrm{t}_{2}\right)\right) \mathrm{z}^{\Delta}\left(\sigma\left(\mathrm{t}_{2}\right)\right)\right) \int_{\mathrm{t}_{2}}^{\mathrm{t}}\left(\frac{1}{\mathrm{f}(\mathrm{x}(\beta(\mathrm{s})))}\right)^{\Delta} \Delta \mathrm{s}
\end{aligned}
$$

this implies that,

$$
\begin{gathered}
\left(\frac{r(t) z^{\Delta}(t)}{f(x(\beta(t)))}\right) \leq\left(r\left(\sigma\left(t_{2}\right)\right) z^{\Delta}\left(\sigma\left(t_{2}\right)\right)\right)\left(\frac{1}{f(x(\beta(t)))}-\frac{1}{f\left(x\left(\beta\left(t_{2}\right)\right)\right)}\right) \\
r(t) z^{\Delta}(t) \leq\left(r\left(\sigma\left(t_{2}\right)\right) z^{\Delta}\left(\sigma\left(t_{2}\right)\right)\right)\left(1-\frac{f(x(\beta(t)))}{f\left(x\left(\beta\left(t_{2}\right)\right)\right)}\right) \text { for large } t \in\left[t_{0}, \infty\right)_{T}
\end{gathered}
$$

since, $\mathrm{x}$ is non increasing, then we can find $\mathrm{k}(<0) \in \mathrm{R}$ such that

Therefore,

$$
\left(r\left(\sigma\left(\mathrm{t}_{2}\right)\right) \mathrm{z}^{\Delta}\left(\sigma\left(\mathrm{t}_{2}\right)\right)\right)\left(1-\frac{\mathrm{f}(\mathrm{x}(\beta(\mathrm{t})))}{\mathrm{f}\left(\mathrm{x}\left(\beta\left(\mathrm{t}_{2}\right)\right)\right)}\right) \leq \mathrm{kfor} \text { all } \mathrm{t} \in\left[\mathrm{t}_{2}, \infty\right)_{\mathrm{T}} .
$$

$\operatorname{Orz}^{\Delta}(\mathrm{t}) \leq \frac{\mathrm{k}}{\mathrm{r}(\mathrm{t})}$

$$
r(t) z^{\Delta}(t) \leq k
$$

Thus, for large $t \in\left[t_{2}, \infty\right)_{T}$, we have

$$
z(t)-z\left(t_{2}\right) \leq k \int_{t_{2}}^{t} \frac{1}{r(s)} \Delta s
$$
theorem.

which implies thatz $(t) \rightarrow-\infty \quad$ as $t \rightarrow \infty$, a contradiction toz $(t)>0$.This completes the proof of the

Example3.13.Let $\mathrm{T}=\mathrm{hZ}$, where $\mathrm{h}$ is a ratio of odd positive integers and consider the following h-difference equation

$\Delta_{h}\left[e^{-t} \Delta_{h}(x(t)+x(t-h))\right]+\frac{\left(e^{h}-1\right)\left(1+e^{-h}\right) e^{-6 h}}{h^{2}} e^{t} x^{3}(t-2 h)=0$, for $t \geq 2 h$.

It is easy to see that equation (3.14) satisfies all the conditions of Theorem (3.12).Hence every solution of equation (3.14) oscillatory or weakly oscillatory. In particularx $(t)=(-1)^{t} \mathrm{e}^{\mathrm{t}}$ is a solution of equation (3.14).

\section{Behavior Of Solutions In $\mathrm{M}^{+}$AndM ${ }^{-}$}

Theorem4.1.With respect to the dynamic equation (1.1), assume that (vii), (ix), (x) and (xi) are hold. Then for every solution $x \in \mathrm{M}^{-}$, we havelim $\mathrm{x} \rightarrow \infty \mathrm{x}(\mathrm{t})=0$.

Proof. Proceeding as in the proof of Theorem 3.5, we have

$$
\int_{z(t)}^{z\left(t_{1}\right)} \frac{d u}{f(u)} \geq \int_{z\left(t_{1}\right)}^{z(t)}-\frac{\Delta u}{f(u)} \geq \int_{t_{1}}^{t} \frac{1}{r(s) f((1+p(s)))} \int_{t_{1}}^{s} q(\tau) \Delta \tau \Delta s
$$

Using(xi), we obtain

$$
\limsup _{\mathrm{t} \rightarrow \infty} \int_{z(\mathrm{t})}^{\mathrm{z}\left(\mathrm{t}_{1}\right)} \frac{\mathrm{du}}{\mathrm{f}(\mathrm{u})}=\infty
$$

This implies thatlim $\mathrm{t}_{\rightarrow \infty} \mathrm{z}(\mathrm{t})=0$, because $\mathrm{z}(\mathrm{t}) \geq \mathrm{x}(\mathrm{t})$ and $\mathrm{x}$ is monotonic.This completes the proof of the theorem.

Theorem4.2. With respect to the dynamic equation (1.1),assume that (i), (iv) andp(t) is bounded hold. If (xv) $\limsup _{\mathrm{t} \rightarrow \infty} \int_{\mathrm{t}_{0}}^{\mathrm{t}} \mathrm{q}(\mathrm{s}) \int_{\mathrm{t}_{0}}^{\mathrm{s}} \frac{1}{\mathrm{r}(\tau)} \Delta \tau \Delta \mathrm{s}=\infty$. Then every solution of (1.1) in the class $\mathrm{M}^{+}$is unbounded.

Proof. Let $\mathrm{x}$ be a solution of (1.1) such that $\in \mathrm{M}^{+}$. Proceeding as in the proof of Theorem3.1,bydefining $\mathrm{z}(\mathrm{t})$ as in equation (3.1), we see that $\mathrm{z}(\mathrm{t})>0$ and $\mathrm{z}^{\Delta}(\mathrm{t}) \geq 0$ for all $\mathrm{t} \in\left[\mathrm{t}_{1}, \infty\right)_{T}$ due to (i). Then from equation (1.1), we obtain equation (3.2). For the function

we have,

$$
w(t)=-\frac{r(t) z^{\Delta}(t)}{f(x(\beta(t)))} \int_{t_{1}}^{t} \frac{1}{r(s)} \Delta s
$$

$$
w^{\Delta}(t)=-\left(r(t) z^{\Delta}(t)\right)^{\Delta}\left(\frac{1}{f(x(\beta(t)))} \int_{t_{1}}^{t} \frac{1}{r(s)} \Delta s\right)-\left(r(\sigma(t)) z^{\Delta}(\sigma(t))\right)\left(\frac{1}{f(x(\beta(t)))} \int_{t_{1}}^{t} \frac{1}{r(s)} \Delta s\right)^{\Delta}
$$




$$
\begin{aligned}
=\mathrm{q}(\mathrm{t}) \int_{\mathrm{t}_{1}}^{\mathrm{t}} \frac{1}{\mathrm{r}(\mathrm{s})} \Delta \mathrm{s}-\left(\mathrm{r}(\sigma(\mathrm{t})) \mathrm{z}^{\Delta}(\sigma(\mathrm{t}))\right)\left(\frac{1}{\mathrm{f}(\mathrm{x}(\beta(\mathrm{t})))}\left(\int_{\mathrm{t}_{1}}^{\mathrm{t}} \frac{1}{\mathrm{r}(\mathrm{s})} \Delta \mathrm{s}\right)^{\Delta}\right)- \\
\quad\left(\mathrm{r}(\sigma(\mathrm{t})) \mathrm{z}^{\Delta}(\sigma(\mathrm{t}))\right)\left[\int_{\mathrm{t}_{1}}^{\sigma(\mathrm{t})} \frac{1}{\mathrm{r}(\mathrm{s})} \Delta \mathrm{s}\left(\frac{1}{\mathrm{f}(\mathrm{x}(\beta(\mathrm{t})))}\right)^{\Delta}\right]
\end{aligned}
$$

Implies that,

$$
\begin{gathered}
\mathrm{w}^{\Delta}(\mathrm{t}) \geq \mathrm{q}(\mathrm{t}) \int_{\mathrm{t}_{1}}^{\mathrm{t}} \frac{1}{\mathrm{r}(\mathrm{s})} \Delta \mathrm{s}-\left(\mathrm{r}(\mathrm{t}) \mathrm{z}^{\Delta}(\mathrm{t})\right)\left(\frac{1}{\mathrm{r}(\mathrm{t}) \mathrm{f}(\mathrm{x}(\beta(\mathrm{t})))}\right)-\left(\mathrm{r}(\sigma(\mathrm{t})) \mathrm{z}^{\Delta}(\sigma(\mathrm{t}))\right)\left[\int_{\mathrm{t}_{1}}^{\sigma(\mathrm{t})} \frac{1}{\mathrm{r}(\mathrm{s})} \Delta \mathrm{s}\left(\frac{1}{\mathrm{f}(\mathrm{x}(\beta(\mathrm{t})))}\right)^{\Delta}\right] \\
\geq \mathrm{q}(\mathrm{t}) \int_{\mathrm{t}_{1}}^{\mathrm{t}} \frac{1}{\mathrm{r}(\mathrm{s})} \Delta \mathrm{s}-\frac{\mathrm{z}^{\Delta}(\mathrm{t})}{\mathrm{f}(\mathrm{x}(\beta(\mathrm{t})))}-\left(\mathrm{r}(\sigma(\mathrm{t})) \mathrm{z}^{\Delta}(\sigma(\mathrm{t}))\right)\left(\int_{\mathrm{t}_{1}}^{\sigma(\mathrm{t})} \frac{1}{\mathrm{r}(\mathrm{s})} \Delta \mathrm{s}\right)\left(\frac{1}{\mathrm{f}(\mathrm{x}(\beta(\mathrm{t})))}\right)^{\Delta} \\
\mathrm{w}^{\Delta}(\mathrm{t}) \geq \mathrm{q}(\mathrm{t}) \int_{\mathrm{t}_{1}}^{\mathrm{t}} \frac{1}{\mathrm{r}(\mathrm{s})} \Delta \mathrm{s}-\frac{\mathrm{z}^{\Delta}(\mathrm{t})}{\mathrm{f}(\mathrm{x}(\beta(\mathrm{t})))}
\end{gathered}
$$

Integrating the above inequality from $t_{1}$ to $t$, we get

$$
\mathrm{w}(\mathrm{t}) \geq \int_{\mathrm{t}_{1}}^{\mathrm{t}} \mathrm{q}(\mathrm{s}) \int_{\mathrm{t}_{1}}^{\mathrm{s}} \frac{1}{\mathrm{r}(\tau)} \Delta \tau \Delta \mathrm{s}-\int_{\mathrm{t}_{1}}^{\mathrm{t}} \frac{\mathrm{z}^{\Delta}(\mathrm{s})}{\mathrm{f}(\mathrm{x}(\beta(\mathrm{s})))} \Delta \mathrm{s}(4.15)
$$

As the function $\frac{\mathrm{z}^{\Delta}(\mathrm{t})}{\mathrm{f}(\mathrm{x}(\beta(\mathrm{t})))}$ is positive for $\mathrm{t} \in\left[\mathrm{t}_{1}, \infty\right)_{\mathrm{T}}$, then

$$
\lim _{\mathrm{t} \rightarrow \infty} \int_{\mathrm{t}_{1}}^{\mathrm{t}} \frac{\mathrm{z}^{\Delta}(\mathrm{s})}{\mathrm{f}(\mathrm{x}(\beta(\mathrm{s})))} \Delta \text { sexists. }
$$

Assume that $\lim _{\mathrm{t} \rightarrow \infty} \int_{\mathrm{t}_{1}}^{\mathrm{t}} \frac{\mathrm{z}^{\Delta}(\mathrm{s})}{\mathrm{f}(\mathrm{x}(\beta(\mathrm{s})))} \Delta \mathrm{s}=\mathrm{k}<\infty$. Taking into account(xv), and from (4.15) we get

$$
\limsup _{t \rightarrow \infty} w(t)=\infty,
$$

Which gives a contradiction, because $\mathrm{w}$ is negative for all $\mathrm{t} \in\left[\mathrm{t}_{1}, \infty\right)_{\mathrm{T}}$. Thus

Consequently,

$$
\lim _{\mathrm{t} \rightarrow \infty} \int_{\mathrm{t}_{1}}^{\mathrm{t}} \frac{\mathrm{z}^{\Delta}(\mathrm{s})}{\mathrm{f}(\mathrm{x}(\beta(\mathrm{s})))} \Delta \mathrm{s}=\infty .(4.16)
$$

$$
\begin{aligned}
& \text { From (4.16), we get } \\
& \qquad \begin{array}{r}
\lim _{\mathrm{t} \rightarrow \infty} \mathrm{z}(\mathrm{t})=\infty . \\
\operatorname{Sincez}(\mathrm{t})=\mathrm{x}(\mathrm{t})+\mathrm{p}(\mathrm{t}) \mathrm{x}(\alpha(\mathrm{t})) \text { andx is non negative, we have } \\
\mathrm{z}(\mathrm{t}) \leq(1+\mathrm{p}(\mathrm{t})) \mathrm{x}(\mathrm{t})
\end{array}
\end{aligned}
$$

$$
\begin{gathered}
\lim _{t \rightarrow \infty} \int_{t_{1}}^{t} \frac{z^{\Delta}(s)}{f(x(\beta(s)))} \Delta s \leq \frac{1}{f(x(\beta(s)))} \int_{t_{1}}^{t} z^{\Delta}(s) \Delta s \\
=\frac{1}{f(x(\beta(s)))}\left(z(t)-z\left(t_{1}\right)\right)
\end{gathered}
$$

From above equation, we have

$$
\lim _{t \rightarrow \infty} x(t)=\infty \text {. }
$$

This completes the proof of the theorem

Corollary4.3. Assume that (iv), (vii), (viii), (ix), (xi), (xiv) and (xv) hold. Then everybounded solution of (1.1) is either oscillatory or weakly oscillatory.

Proof: The proof follows from Theorems 3.5 and 4.2 .

\section{Conclusion}

Inthis paper, we studied the non-existence solutions of class $\mathrm{M}^{+}$and $\mathrm{M}^{-}$for the ranges $\mathrm{p}(\mathrm{t}) \geq 0$ and $-1<p(t) \leq 0$, and the non-existence solutions of a class WOS is studied for $\mathrm{p}(\mathrm{t})=-1$ by taking some restriction in delays. Theexistence solutions of a class OS and WOS has been studied by the way, so that the class $\mathrm{M}^{+}$andM $\mathrm{M}^{-}$is empty. In section 4 , we have been studied the asymptotic behavior of $\mathrm{M}^{+}$and $\mathrm{M}^{-}$. It would be interesting to study the existence / non-existence of a class $\mathrm{M}^{+}, \mathrm{M}^{-}$, OS and WOS for different ranges $o f p(t)$. In addition, extending such results to higher order equation would also be of interest. 


\section{Journal papers:}

\section{References}

[1]. S. Hilger, Analysis on measure chains: a unified approach to continuous and discrete calculus, Results.Math. 18 (1990), 18-56.

[2]. S. Panigrahi, and P. Rami Reddy, On oscillatory and asymptotic behavior of fourth order non-linearneutral delay dynamic equations, Comp. Math. Appl. 62 (2011), 4258-4271.

[3]. S. Panigrahi, and P. Rami Reddy, Oscillatory and asymptotic behavior of fourth order non-linear neutraldelaydynamic equations,Dynamics of Continuous, Discrete and Impulsive Systems Series A: Mathematical Analysis 20 (2013), 143-163.

[4]. S. Panigrahi, J. R. Graef and P. R. Reddy, Oscillation Results for fourth order nonlinear neutral dynamicequations, Commu. Math. Anal., 15 (2013), 11-28.

[5]. J. R. Graef, S. Panigrahi, and P. Rami Reddy, On oscillatory and asymptotic behavior of fourth ordernonlinear neutral delay dynamic equations with positive and negative coefficients, Math. Slovaca, 64(2014), No. 2, 347-366.

[6]. S. R. Grace, J. R. Graef, S. Panigrahi, and Ercan Tunc, On the oscillatory behavior of even order neutraldelay dynamic equations on time scales,Electron. J. Qual. Theory Differ. Equ. 96 (2012), 1-12.

[7]. E. Thandapani, S. Padmavathi, and S. Pinelas, Classifications of solutions of second-order nonlinearneutral differentialequationsof mixed type, Advances in Difference Equations, 226 (2012), (1-13).

[8]. M. Cecchi, and M. Marini,Oscillatory and non-oscillatory behavior of a second order functional differential equation, Rocky Mountain Journal of Mathematics 22 (1992) No. 4, 1259-1276.

[9]. R. P. Agarwal, M. M. S. Manuel, and E. Thandapani, Oscillatory and non-oscillatory behavior of secondorder neutral delaydifference equations, Math. Comput. Modelling 24 (1996) No. 1. 5-11.

[10]. Sabah Hafez Abdallah, Oscillatory and non-oscillatory behavior of second order neutral delay differentialequations, Appl. Math. Comput. 135 (2003) 333-344.

[11]. E. Thandapani, and M. M. S. Manuel, Summable criteria for a classification of solution of lineardifference equation,Indian J.Pure Appl. Math., 28 (1997) 53-62.

[12]. E. Thandapani, and S. Pandian, Oscillatory and asymptotic behavior of second order functional difference equations, Indian J. Math., 37 (1995) 221-233.

[13]. E. Thandapani, S. Pandian, and B. S. Lalli, Oscillatory and non-oscillatory behavior of second orderfunctional difference equations, Appl. Math. Comput., 70 (1995) 53-66.

[14]. S. Elizabeth, J. R. Graef, P. Sundaram, and E. Thandapani, Classifying non-oscillatory solutions andoscillation of a neutral difference equations, J. Difference Equ. Appl. 11 (2005), 605-615.

\section{Books:}

[15]. M.Bohner, and A. Peterson, Dynamic Equations on Time Scales: An Introduction with Applications,Birkhauser, Boston, 2001.

[16]. M. Bohner, and A. Peterson, Advances in Dynamic Equations on Time Scales, Birkhauser, Boston,2003.

\section{Authors E-mail address:}

1.reddyrami77@gmail.com

2.rsikender.n@gmail.com

3. drmvkrishna5@rediffmail.com 